\title{
VARIACIONES BIOQUÍMICAS E HISTÓLOGICAS ASOCIADAS AL EVENTO REPRODUCTIVO DE LA HEMBRA DE Octopus mimus (MOLLUSCA: CEPHALOPODA)
}

\author{
HISTOLOGICAL AND BIOCHEMICAL VARIATIONS PRODUCED DURING THE \\ REPRODUCTIVE EVENT OF FEMALE Octopus mimus (MOLLUSCA: CEPHALOPODA)
}

\author{
Mauricio Zamora C. \& Alberto Olivares P.
}

\begin{abstract}
ZAMORA, C. M \& OLIVARES, P. A. Variaciones bioquímicas e histológicas asociadas al evento reproductivo de la hembra de Octopus mimus (Mollusca:Cephalopoda). Int. J. Morphol., 22(3):207-216, 2004.

RESUMEN: Octopus mimus presenta modalidad reproductiva tipo semélpara. Días antes de la puesta, las hembras dejan de alimentarse y su metabolismo se sustenta con la energía almacenada en el cuerpo, muriendo después del nacimiento de las paralarvas. Mediante estudio histológico y bioquímico se constataron cambios del tejido muscular, la glándula digestiva y del ovario, asociados al único evento reproductivo de la hembra. Después del desove, el ovario no tiene células germinales que permitan el desarrollo de un nuevo ciclo reproductivo; la glándula digestiva y el músculo presentan atrofia de sus células, con un gran incremento del tejido conectivo en especial de las fibras colágenas. Las proteínas, glúcidos y lípidos de la glándula digestiva y el músculo decrecen en el período comprendido entre la puesta y la eclosión de los huevos. Las drásticas alteraciones bioquímicas y el deterioro estructural irreversible del músculo y glándula digestiva, disminuyen las expectativas de vida, relacionándose con los cambios degenerativos que se desarrollan en la hembra después de la reproducción.
\end{abstract}

PALABRAS CLAVE: 1. Octopus mimus; 2. Reproducción; 3. Hembra; 4. Bioquímica; 5. Histología.

\section{INTRODUCCIÓN}

Octopus mimus Gould, 1852, habita las costas del Pacífico de Sudamérica, desde el norte de Perú hasta Chile central (Guerra et al., 1999). Tiene ciclo vital corto y estrategia reproductiva de tipo semélpara (Cortez et al., 1999). Estos organismos en sus primeras etapas de vida canalizan rápidamente sus reservas de energía en crecimiento y desarrollo pero, posteriormente, sólo a la reproducción.

La reproducción frecuentemente agota la condición de un organismo (estado nutricional del animal) y a su vez la condición puede determinar la ocurrencia y la intensidad de los eventos reproductivos (Silby \& Calow, 1986), aunque generalmente la condición de las especies semélparas, resulta más afectada que la de las iteróparas (Calow, 1979). La hembra de Octopus mimus, días previos a la postura de sus huevos, deja de comer indefinidamente, careciendo de nutrientes exógenos para producir ovocitos maduros, lo cual repercute en su estado de condición, aunque no interfiere en la maduración y reproducción de ellas (Olivares et al., 2001; Castro et al. 2002).
La condición de la hembra de Octopus mimus, tanto en la naturaleza como en cautiverio, se deteriora dramáticamente después del desove y durante el cuidado de los huevos presentando una disminución de la masa muscular y de la glándula digestiva que puede sobrepasar el $25 \%$ del peso total, previo al desove (Cortez et al., 1995; Olivares et al., 1996). Lo anterior es una evidencia indirecta de que durante el ayuno reproductivo, ambos órganos constituyen la reserva de energía para los procesos metabólicos; no obstante las variaciones bioquímicas y tisulares, del músculo y de la glándula, asociadas a la reproducción de Octopus mimus hembra, no han sido determinadas.

Diferentes funciones se han mencionado para la glándula digestiva de los cefalópodos, de las cuales algunas han presentado discrepancias y muchas otras aún no han sido estudiadas (Morales, 1973; Budelmann et al., 1997). Entre ellas, se ha mencionado el rol de reservorio de energía metabólica (Hatfield et al., 1992); sitio de la síntesis y secreción de enzimas digestivas, y también, encargada de la 
digestión, absorción y excreción(Boucad-Camou \& Boucher-Rodoni, 1983). En los cefalópodos Octopus vulgaris y Todarodes pacificus los nutrientes para la fase final de la maduración son aportados por la musculatura corporal y glándula digestiva (O'Dor \& Wells, 1978; Tait, 1986). En estos tejidos somáticos se observaron cambios estructurales y/o bioquímicos durante el proceso reproductivo de las especies Loligo opalescens (Fields, 1965), Loligo vulgaris (Sauer \& Lipinsky 1990), Sepia officinalis (Castro et al., 1992), Illex argentinus (Hatfield et al.), Moroteuthis ingens (Jackson \& Mladenov, 1994) y Photololigo sp. (Moltschaniwskyj, 1997). Sin embargo, las modificaciones detectadas en calamares y sepias, no han sido descritas en octópodos.

En este trabajo, mediante estudio histológico y determinaciones bioquímicas de la musculatura de los brazos y de la glándula digestiva, se analizan las alteraciones producidas en estas estructuras somáticas y se evalúa la función de reservorio de nutrientes para sustentar el metabolismo reproductivo de las hembras de Octopus mimus, en el período comprendido desde el último estadio de la maduración sexual hasta el cuidado de los embriones, que culmina con el nacimiento de las paralarvas.

\section{MATERIAL Y MÉTODO}

En la región de Antofagasta (Lat. 2344'S; Long. $\left.70^{\circ} 28^{\prime} \mathrm{W}\right)$, Chile, se capturaron ejemplares de Octopus mimus, a una profundidad no superior a $25 \mathrm{~m}$. Según el estado macroscópico del ovario, se seleccionaron 99 ejemplares en predesove (estadio final de maduración) y 12 en posdesove (hembras que han finalizado la puesta de huevos y podrían estar en una etapa comprendida desde el inicio del periodo de incubación y cuidado de embriones hasta el posterior nacimiento de las crías); pero a las cuales no se les pudo precisar en que momento del posdesove se encontraban. De entre las hembras en predesove se escogieron 15 que estaban próximas a iniciar la puesta de huevos y que tuvieran el mejor índice de condición. Éstas se mantuvieron en cautiverio para ser analizadas al término del desarrollo embrionario y nacimiento de todas las crías (período posdesove).

Para identificar los estadios de madurez sexual, se utilizó la escala propuesta para Octopus mimus por Olivares et al. (2001) y como indicador del estado de condición la masa de la glándula digestiva (Castro et al., 1992). A cada ejemplar se le realizaron las siguientes mediciones: peso total del animal (PT); peso de la glándula digestiva (PGD); peso de las gónadas (PG) y peso eviscerado (PE). El índice de condición (IC) se determinó utilizando la relación: PGD*100/(PT-PGD) (Cortez et al., 1995).

La denominación de las tres porciones de la glándula digestiva está de acuerdo a la terminología establecida por Mangold \& Young (1998). La primera, es la porción mayoritaria y se denomina glándula digestiva propiamente tal (antes hepatopáncreas o hígado); la segunda se denomina apéndices de los ductos digestivos (antes páncreas) y la última, saco de la tinta (sin modificaciones en su nombre).

Análisis histológico: A cada individuo se le seccionó un trozo de aproximadamente $1 \mathrm{~cm}^{2}$ de ovario, músculo del brazo y glándula digestiva, para fijación en formalina al $10 \%$. Después de 4 horas fueron posfijados en Bouin alcohólico por 24 horas y, posteriormente, procesados mediante técnica histológica corriente e incluidos en parafina (Lillie, 1968). Cortes de $4 \mu \mathrm{m}$ de espesor fueron realizados con micrótomo de rotación y teñidos con Hematoxilina Eosina para descripción histológica y citomorfológica general; Alcian Blue para identificar mucopolisacáridos ácidos y Tricrómica de Arteta, específica para identificar fibras colágenas y tejido conectivo en general (López, et al. 1982).

Análisis bioquímico: Se escogieron para este análisis 14 ejemplares de mayor índice de condición en predesove y 14 de menor condición en posdesove. En cada órgano se determinaron agua, cenizas, lípidos, proteínas y glúcidos totales, para lo cual se excluyó la glándula de la tinta y los apéndices de los ductos de la glándula digestiva. Los análisis se realizaron según la metodología estándar de Schmidt-Hebbel (1981).

El equivalente calórico ( $\mathrm{Kcal} / \mathrm{g}$ de peso seco) de cada uno de los compuestos, se calculó aplicando los factores propuestos por O'Dor et al. (1984): 4,7 para proteínas, 9,0 para lípidos y 4,0 para los glúcidos.

\section{RESULTADOS}

Glándula digestiva. La glándula digestiva es un órgano compacto, unilobulado, compuesto por tres porciones glandulares, separadas entre sí por un delgado tabique de tejido conectivo (Fig.1). La glándula digestiva propiamente dicha, es la más voluminosa y constituye sobre el $90 \%$ de la masa total de la glándula digestiva. El parénquima de esta glándula, está constituida por acinos, que presentan luz amplia, de forma variable al corte, alargados, de contornos circulares e irregulares. Tapizando el interior de cada acino, se encontraron los siguientes 5 tipos celulares: 

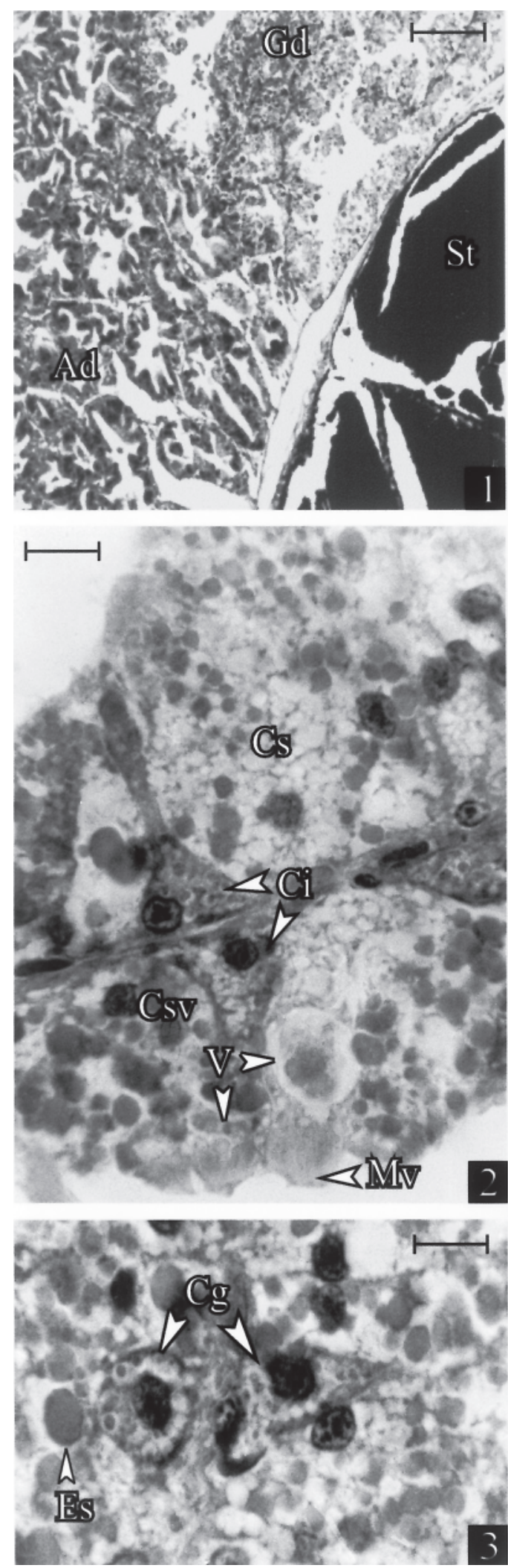
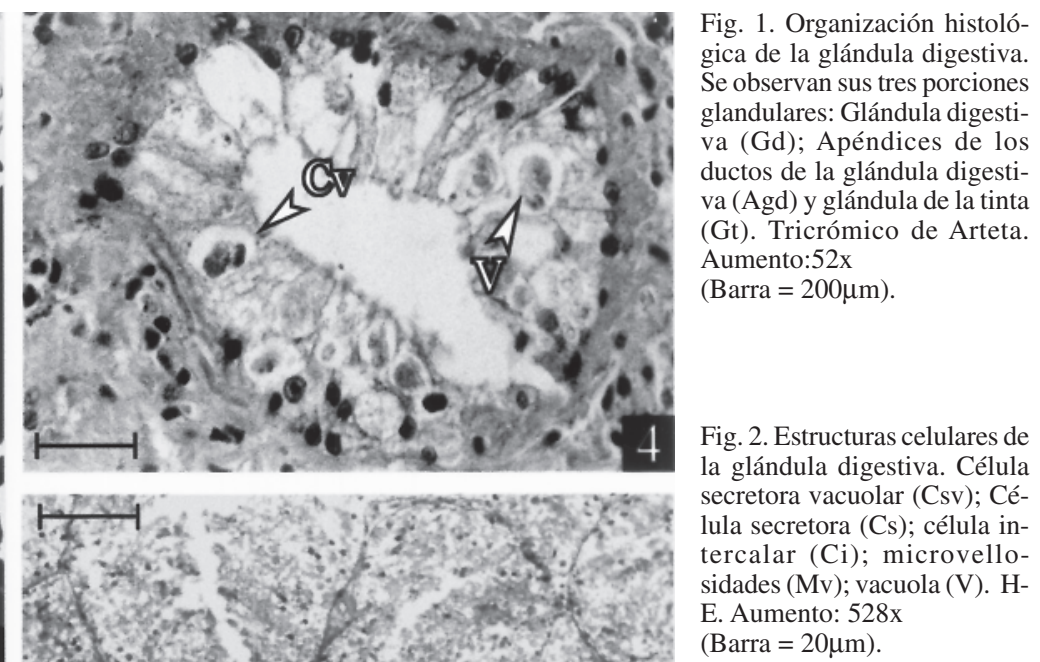

Fig. 1. Organización histológica de la glándula digestiva. Se observan sus tres porciones glandulares: Glándula digestiva (Gd); Apéndices de los ductos de la glándula digestiva (Agd) y glándula de la tinta (Gt). Tricrómico de Arteta. Aumento:52x $($ Barra $=200 \mu \mathrm{m})$

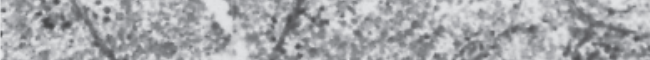

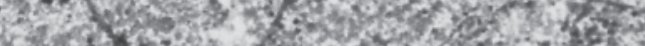

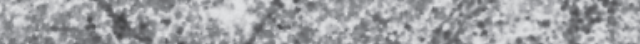

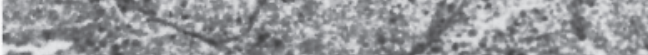

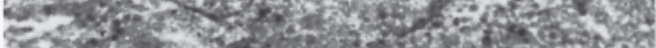

(1)
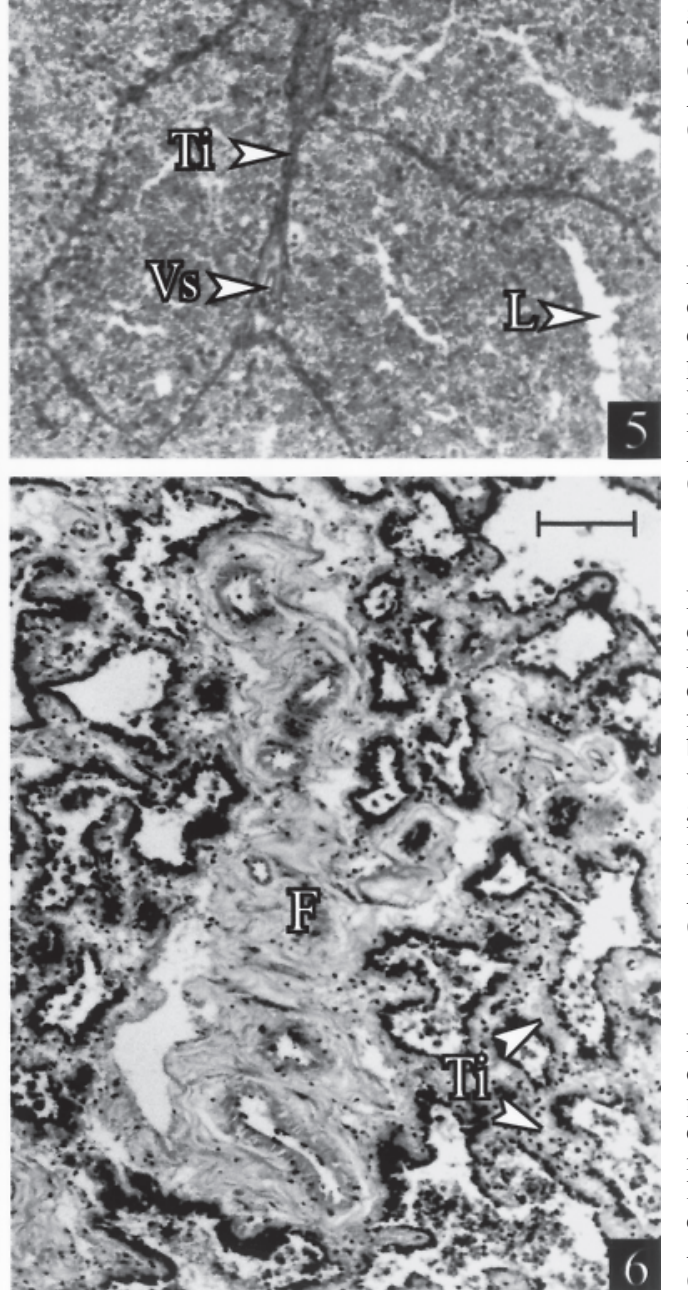

Fig. 3. Célula de citoplasma granular $(\mathrm{Cg})$ de la glándula digestiva. Esfera secretora (Es). H-E.

Aumento: 1320x

(Barra $=7 \mu \mathrm{m})$.

Fig. 4. Estructura de los acinos de la glándula digestiva en la etapa de posdesove, en la cual predominan las Células vacuolares $(\mathrm{Cv})$. Vacuola $(\mathrm{V})$. H-E.

Aumento: $132 \mathrm{x}$

(Barra $=80 \mu \mathrm{m})$.

Fig. 5. Vista general de la glándula digestiva en predesove. Los tabiques interacinares (Ti) están formados por delgadas fibras colágenas, entre los tabiques es posible observar los vasos sanguíneos (Vs) encargados de nutrir al órgano; lumen del acino (L). Tricrómico de Arteta.

Aumento: 52x $($ Barra $=200 \mu \mathrm{m})$.

Fig. 6. Desorganización tisular de la glándula digestiva después del desove. Se observa el engrosamiento de los tabiques interacinares (Ti), producto de la abundante fibrosis de tipo colágena (F). H-E. Aumento: 52x

$($ Barra $=200 \mu \mathrm{m})$. 
a) Células secretoras: (Fig. 2) son muy abundantes. Poseen gran cantidad de formas variando desde prismáticas a piramidales. Su núcleo es basal y esférico. El citoplasma presenta numerosas gotas y/o granulaciones acidófilas (gotas rojas) de apariencia similar a las granulaciones de tipo cimógena. En el borde apical, la célula presenta largas microvellosidades que, en algunos casos aparecen compactadas. Estas microvellosidades son muy lábiles, destruyéndose fácilmente por efecto de la técnica histológica.

b) Células secretoras vacuolares: (Fig. 2) se caracterizan por presentar secreción cimógena y vacuolas, estas últimas con una o más gotas de color pardo amarillo.

c) Células de citoplasma granuloso: (Fig. 3) se caracterizan por presentar en su citoplasma finas y numerosas granulaciones acidófilas, además, por ser más pequeñas que el resto de los tipos celulares y de forma irregular, mayoritariamente piramidal o esféricas. Su núcleo es basal y esférico. El nucléolo presenta cromatina fina, es esférico y excéntrico. Estas células son escasas y difíciles de observar.

d) Células intercalares: (Fig. 2) también presentan citoplasma granuloso, pero a diferencia del anterior tipo celular, son delgadas y estrechas, insinuándose entre las células predominantes. Son escasas y difíciles de observar.

e) Células vacuolares: (Fig. 4) Se caracterizan por presentar una o más vacuolas, generalmente es una sola y grande, situada en la región apical, que contiene numerosas granulaciones o gotas pardas más pequeñas que se fusionan para formar una gruesa gota de aspecto oleoso que se tiñe de color pardo amarillo con Hematoxilina-Eosina y azul con Alcian blue y Arteta. Carecen de secreción cimógena. En el borde apical de la célula, las microvellosidades se observan con mayor nitidez que en las células que presentan secreción enzimática (gotas rojas).

En el tejido conectivo interacinar se ubican vasos sanguíneos y escasas fibras colágenas (Fig. 5).

La glándula digestiva después del desove, desarrolla cambios en su organización (Fig. 4). Los acinos se comprimen, compactándose y disminuyendo su luz. La secreción de gránulos de cimógeno disminuye, predominando en las células vacuolares. En los tabiques acinares, se observó una fibrosis de tipo colágena (Fig. 6), en torno a los vasos sanguíneos y que es progresiva con el tiempo de posdesove.

En ejemplares con más de 50 días posdesove, las células vacuolares pierden su porción apical, quedando reducidas a células cúbicas. No se observaron células secretoras, ni secretoras vacuolares. Los espacios interacinares presentan incremento del tejido conectivo, con predominio de las fibras colágenas. La fibrosis fue más intensa, principalmente alrededor de los vasos sanguíneos del parénquima de la glándula digestiva.

Los pesos promedios húmedo y seco (Tabla I) disminuyeron durante el posdesove en $90,4 \%$ y $92,4 \%$ respectivamente, aunque se registraron pesos húmedos extremos de $300 \mathrm{~g}$ antes del desove y 4,3 $\mathrm{g}$ en el posdesove. En la etapa de posdesove, los porcentajes de agua y cenizas aumentaron en un $11,8 \%$ y $7,2 \%$ respecto del posdesove (Tabla II). Las cenizas de los órganos analizados presentaron una coloración celeste-verdosa tanto en predesove como en posdesove.

La glándula digestiva en predesove está compuesta mayoritariamente por proteínas y lípidos. Después del desove, el porcentaje de proteínas aumentó, el de lípidos disminuyó notoriamente y el de glúcidos fue similar al registrado antes del desove. La inversión calórica en reproducción fue mayoritariamente lipídica $(171,9 \mathrm{Kcal} / \mathrm{g})$ y proteica (96,4 Kcal/g), mientras que la energía proporcionada por los glúcidos (33,6 Kcal/g.) fue la menor (Tabla III).

Musculatura del brazo: La musculatura del brazo de Octopus mimus está compuesta por diferentes capas de células musculares que discurren en sentido longitudinal, circular, perpendicular y oblicuamente al eje mayor del brazo, separados entre sí por tejido conectivo. Las células (fibras) musculares son cilíndricas, presentan núcleo ovoide central y a corte transversal se le detectan finas estriaciones (Figs. 8 y 9 ).

En la etapa de posdesove, las fibras musculares mostraron una disminución relativa del grosor, carencia de estriaciones y con frecuencia núcleos heteropicnóticos. A nivel intersticial se produjo un aumento del tejido conectivo, con predominancia de las fibras colágenas. (Fig. 10).

El peso promedio del tejido muscular (peso eviscerado) disminuyó en $22,8 \%$ durante el período posdesove. Se detectaron valores extremos individuales de $2.594 \mathrm{~g}$ en predesove y $804 \mathrm{~g}$ en posdesove, correspondiente a una disminución máxima del 69,0\%. Los porcentajes de agua y de cenizas aumentaron después del desove (Tabla III). El tejido muscular en pre y posdesove está compuesto mayoritariamente por proteínas y, después, en menor grado por glúcidos; mientras que los lípidos están en un porcentaje muy bajo. Después del desove las proteínas incrementaron su composición porcentual, los glúcidos disminuyeron notoriamente y los lípidos muy poco. La inversión calórica en reproducción fue mayoritariamente proteica $(282,3 \mathrm{Kcal} / \mathrm{g})$ y glucosídica $(223,5$ $\mathrm{Kcal} / \mathrm{g}$ ), mientras que la energía proporcionada por los lípidos (13,5 Kcal/g.) fue muy baja (Tabla III). 

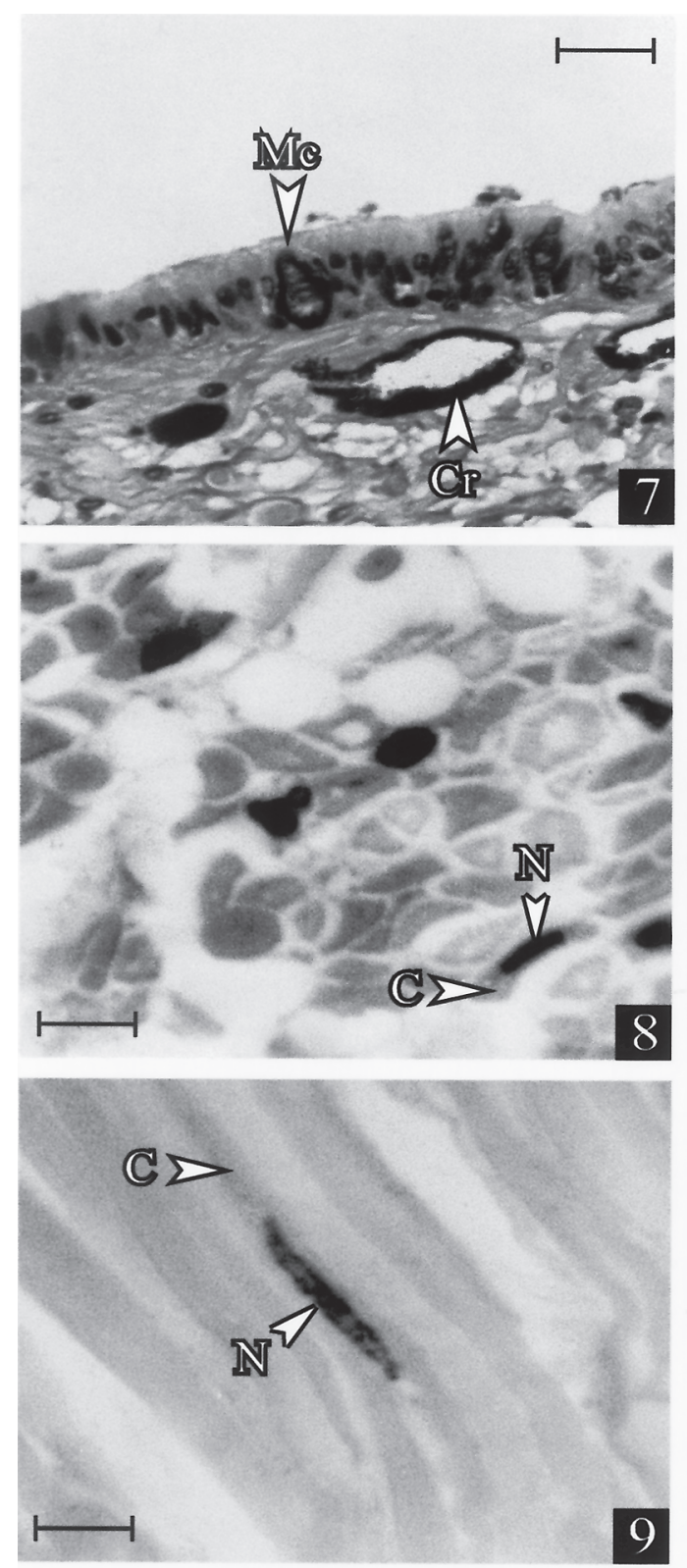

9

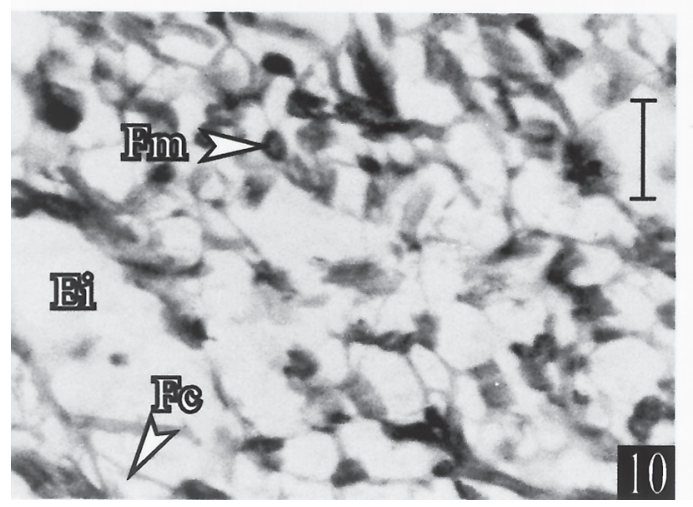

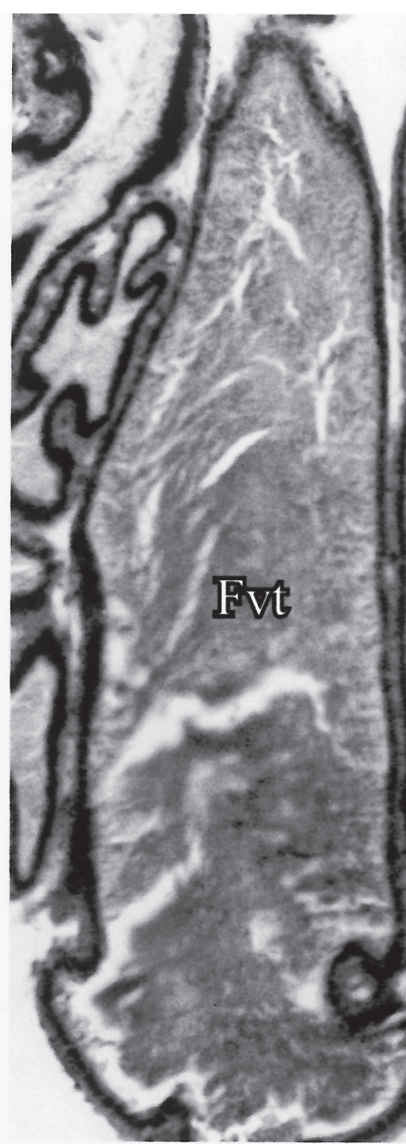
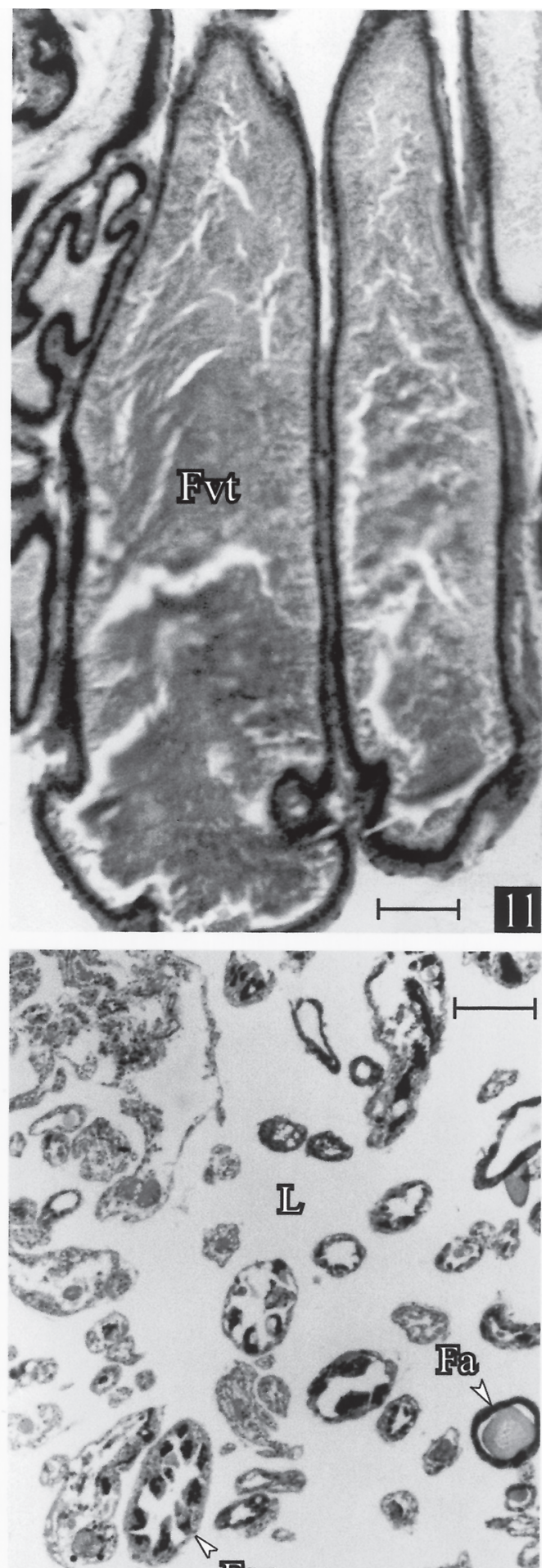

3

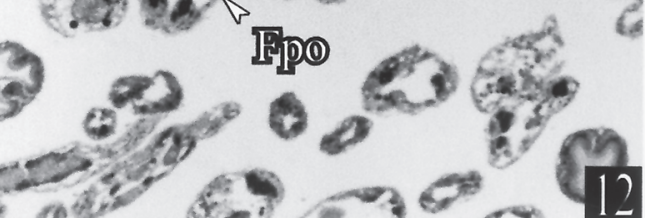

Fig. 7. Sección de epidermis del brazo de $O$. mimus. Se observa el epitelio que recubre la superficie del brazo y algunas células secretoras intraepiteliales de tipo mucosa $(\mathrm{Cm})$. En la zona subepitelial se observan los cromatóforos $(\mathrm{Cr})$. H-E.

Aumento: 132x $($ Barra $=80 \mu \mathrm{m})$.

Fig. 8. Corte transversal de las fibras musculares estriadas del brazo. Se observa el núcleo ovoide y central de los miocitos. Citoplasma (C); núcleo (N). H-E.

Aumento: 1320x

$($ Barra $=7 \mu \mathrm{m})$.

Fig. 9. Corte longitudinal de las fibras musculares del brazo. Citoplasma (C); núcleo $(\mathrm{N})$. H-E. Aumento: 1320x $($ Barra $=7 \mu \mathrm{m})$.

Fig. 10. Desorganización del tejido muscular después del desove; fibras musculares $(\mathrm{Fm})$; fibras colágenas $(\mathrm{Fc})$; espacios intercelulares (Ei). H-E. Aumento: $528 \mathrm{x}$ $($ Barra $=20 \mu \mathrm{m})$.

Fig. 11. Estructura ovárica en predesove. Se observan los folículos vitelinos terminales (Fvt). H-E.

Aumento: 132x $($ Barra $=80 \mu \mathrm{m})$.

Fig. 12. Estructura ovárica en posdesove. Se encuentra caracterizada por la presencia de numerosos folículos posovulatorios (Fpo), también es posible observar folículos atrésicos $(\mathrm{Fa})$; lumen ovárico (L). H-E.

Aumento: 132x

$($ Barra $=80 \mu \mathrm{m})$. 
Ovario: El ovario previo al desove se caracteriza por la presencia de gran cantidad de folículos en final de vitelogénesis y ovocitos preovulatorios. Los folículos vitelinos terminales (Fig. 11) tienen el citoplasma lleno de vitelo, miden $362,69 \mu \mathrm{m}$ de ancho y 1331,05 $\mu \mathrm{m}$ de largo. En estos folículos se produce la desorganización de las glándulas intraepiteliales debido a la regresión de los pliegues del epitelio folicular. Se evidencia el estrechamiento del extremo basal del ovocito que dará origen al típico filamento coriónico del ovocito maduro de Octopus spp. Los ovocitos preovulatorios son más grandes $(532,61 \mu \mathrm{m}$ de ancho; $1544,21 \mu \mathrm{m}$ de largo) que los folículos vitelinos terminales y están delimitados por un epitelio folicular cúbico a plano. Característico de estos ovocitos es que una vez desorganizado completamente el epitelio glandular, disminuyen su altura y vuelven a constituir un epitelio folicular plano. El filamento coriónico se encuentra bien desarrollado.

La estructura microscópica del ovario desovado se caracteriza por la presencia de folículos posovulatorios y ovocitos residuales, en degeneración por la actividad de las células fagocíticas. Además es común en este estado la presencia de folículos atrésicos (Fig. 12).

Tabla I. Variaciones del peso corporal y de algunos órganos de Octopus mimus hembra, en estadios predesove y posdesove.

\begin{tabular}{lcc} 
Pesos $(\mathrm{g})$ & $\begin{array}{c}\text { Predesove } \\
(\mathrm{x} \pm \mathrm{s})\end{array}$ & $\begin{array}{c}\text { Posdesove } \\
(\mathrm{x} \pm \mathrm{s})\end{array}$ \\
\hline Total húmedo & $1680,0 \pm 265,0$ & $1342,5 \pm 290,0$ \\
Eviscerado & $1615,0 \pm 330,7$ & $1246,0 \pm 355,2$ \\
Húmedo glándula digestiva & $169,0 \pm 34,2$ & $16,2 \pm 7,7$ \\
Seco glándula digestiva & $55,0 \pm 46,3$ & $4,2 \pm 2,8$ \\
Húmedo musculatura brazo & $1442,0 \pm 203.5$ & $1112,7 \pm 155,2$ \\
Seco músculo & $233,6 \pm 54,3$ & $118,6 \pm 40,3$ \\
Húmedo ovario & $174,4 \pm 59,6$ & $11,9 \pm 6,7$ \\
Seco ovario & $65,6 \pm 21,2$ & $1,3 \pm 2,4$ \\
\hline
\end{tabular}

La disminución del peso promedio del ovario después del desove fue notable $(93,2 \%)$. El porcentaje de agua aumentó en un $27 \%$ y el de las cenizas un 3,1\%. (Tabla I). Los valores individuales extremos fueron de 200,8 g antes del desove y $1,3 \mathrm{~g}$ después del desove, variación que revela una disminución extrema del 99,3\% del peso del ovario.

El ovario está formado mayoritariamente por proteínas y glúcidos. El contenido lipídico en el ovario fue bajo. Los contenidos porcentuales de proteínas y lípidos aumentaron después del desove y los glúcidos disminuyeron. La inversión calórica promedio del ovario fue mayormente proteica y glucosídica (Tabla III).

Índice de condición (IC). El valor promedio del IC (Tabla IV), antes del desove, fue de 6,07, mientras que el índice de condición de las hembras desovadas disminuyó a casi un sexto de lo observado antes del desove. Entre los valores máximo y mínimo del IC también hubo diferencias notables, pues estos índices corresponden a la hembra de mejor condición, en contraste con la hembra de menor condición.

Tabla II. Análisis bioquímico de la de la glándula digestiva, músculo y ovario en hembras Octopus mimus, en estadios predesove y posdesove.

\begin{tabular}{llcc} 
& & Predesove $\%$ & Posdesove \% \\
\hline \multirow{4}{*}{ Glándula } & Agua & $62,3 \pm 4,5$ & $74,1 \pm 5,1$ \\
digestiva & Cenizas & $6,1 \pm 1,3$ & $13,3 \pm 2,1$ \\
& Proteínas & $41,9 \pm 8,6$ & $60,3 \pm 7,2$ \\
& Lípidos & $35,5 \pm 10,9$ & $10,1 \pm 4,6$ \\
& Glúcidos & $16,5 \pm 10,1$ & $16,3 \pm 5,5$ \\
\hline \multirow{4}{*}{ Músculo } & Agua & $83,8 \pm 1,1$ & $89,4 \pm 1,5$ \\
& Cenizas & $5,2 \pm 0,2$ & $12,3 \pm 2,1$ \\
& Proteínas & $64,5 \pm 4,9$ & $76,4 \pm 4,3$ \\
& Lípidos & $1,1 \pm 0,2$ & $0,9 \pm 0,3$ \\
& Glúcidos & $29,2 \pm 5,0$ & $10,4 \pm 2,4$ \\
\hline \multirow{4}{*}{ Ovario } & Agua & $62,4 \pm 4,5$ & $89,4 \pm 1,7$ \\
& Cenizas & $3,3 \pm 0,5$ & $6,4 \pm 2,4$ \\
& Proteínas & $47,6 \pm 8,1$ & $62,1 \pm 9,6$ \\
& Lípidos & $4,0 \pm 0,5$ & $12,3 \pm 1,1$ \\
& Glúcidos & $45,1 \pm 8,3$ & $19,2 \pm 3,1$ \\
\hline
\end{tabular}

Tabla III. Contenido energético de la glándula digestiva, músculo y ovario de Octopus mimus hembra, en estadios predesove y posdesove y el aporte energético de estos órganos después del desove.

\begin{tabular}{lllll} 
& $\begin{array}{l}\text { Predesove } \\
(\mathrm{Kcal})(\mathrm{x} \pm \mathrm{s})\end{array}$ & $\begin{array}{l}\text { Posdesove } \\
(\mathrm{Kcal})(\mathrm{x} \pm \mathrm{s})\end{array}$ & $\begin{array}{c}\text { Aporte Energético } \\
(\mathrm{Kcal})\end{array}$ \\
\hline \multirow{3}{*}{$\begin{array}{l}\text { Glándula } \\
\text { digestiva }\end{array}$} & Proteínas & $108,3 \pm 22,2$ & $11,9 \pm 1,4$ & 96,4 \\
& Lípidos & $175,7 \pm 53,9$ & $3,8 \pm 1,7$ & 171,9 \\
& Elúcidos & $36,3 \pm 22,2$ & $2,7 \pm 0,9$ & 33,6 \\
\multirow{2}{*}{ Músculo } & Proteínas & $320,3 \pm 32,8$ & $18,4 \pm 1,4$ & 301,9 \\
& Lípidos & $708,2 \pm 60,2$ & $425,9 \pm 26,7$ & 282,3 \\
& Glúcidos & $23,1 \pm 4,7$ & $9,6 \pm 3,6$ & 13,5 \\
& Energía total & $272,8 \pm 22,2$ & $49,3 \pm 12,7$ & 223,5 \\
\multirow{2}{*}{ Ovario } & Proteínas & $1004,1 \pm 38,7$ & $484,8 \pm 8,1$ & 519,3 \\
& Lípidos & $23,6 \pm 3,0$ & $3,8 \pm 0,6$ & 143,0 \\
& Glúcidos & $118,3 \pm 21,8$ & $1,4 \pm 0,1$ & 22,2 \\
& Energía total & $288,7 \pm 38,7$ & $1,00 \pm 0,2$ & 117,3 \\
\hline
\end{tabular}

Tabla IV: Valores promedios, mínimos y máximos individuales del índice de condición (IC) registrados en Octopus mimus antes y después del desove.

\begin{tabular}{ccc}
\hline \multicolumn{3}{c}{ Predesove } \\
IC promedio & IC mínimo & IC máximo \\
$6,07 \pm 4,75$ & 1,22 & 22,81 \\
& Posdesove &
\end{tabular}

\begin{tabular}{lll}
$1,24 \pm 1,04$ & 0,27 & 3,57 \\
\hline
\end{tabular}




\section{DISCUSIÓN}

Octopus mimus hembra durante el ayuno reproductivo perdió peso corporal, debido a que su metabolismo fue mantenido con las reservas energéticas del tejido muscular y de la glándula digestiva. La disminución de peso de la glándula digestiva también ha sido descrita para Octopus vulgaris, Todarodes japonicus (Tait) y Octopus tehuelchus (Pollero \& Iribarne, 1988), pero el mínimo detectado en estas especies y en Octopus mimus en estado natural (Cortez et al., 1995), es superior al detectado en Octopus mimus mantenidas en cautiverio, debido a que estas, están muy débiles y vulnerables a la depredación, esto lleva a que sea poco probable poder encontrarlas en su ambiente natural.

La glándula digestiva tiene una compleja estructura histológica por su multifuncionalidad y diferentes cambios asociados a la digestión (Bidder, 1950, 1957; BoucherRodoni \& Mangold, 1977; Boucad-Camou \& Yim, 1980). La absorción en esta glándula (Bidder, 1966; Boucad-Camou et al., 1976; Boucher-Rodoni \& Mangold; O'Dor et al.) está facilitada por la válvula de doble dirección, permitiendo el flujo directo de los nutrientes desde el ciego intestinal hacia las células digestivas (Semmens, 1993). La superficie de absorción en las células digestivas de Octopus mimus está aumentada por las microvellosidades, las cuales en coincidencia al funcionamiento celular, eran relativamente más largas en las células digestivas de animales con alto contenido digestivo, respecto de las de las hembras en ayuno reproductivo. Aunque no fue evaluada la ciclicidad periódica de las microvellosidades de las células digestivas, asociada a la función de absorción, descrita en Octopus spp (Bidder, 1957), se puede inferir que la ingesta alimenticia, en hembras Octopus mimus, induce una hipertrofia y el ayuno desencadena la atrofia de las microvellosidades. Además, en las células digestivas de Octopus mimus no fueron constatados los cilios descritos en las del Octópodo Pteroctopus tetracirrhus (Morales). Los cilios no tienen relación directa con la absorción, pero pueden facilitar el desplazamiento de los nutrientes y la ingesta del alimento en numerosos invertebrados. A la absorción por endocitosis le sigue la digestión intracelular dentro de grandes heterolisosomas (Cuenot, 1907; Semmens et al., 1995) y el aprovechamiento directo de los nutrientes de la digestión intracelular, haciendo de la glándula digestiva un sistema autónomo (Boucad-Camou \& Yim). Estudios histológicos y morfométricos indican que el tamaño y número de las vacuolas de secreción y degradación enzimática en ellas, están relacionados con la digestión (Tazi et al., 1991) y consecuentemente en Octopus mimus estas vacuolas fueron detectadas solamente en las hembras en predesove y no en las que permanecieron en ayuno posdesove.
Además de las variaciones asociadas a la hipofuncionalidad de las células digestivas, en la glándula se produjo una progresiva síntesis y depósito de fibras colágenas, entre los tabiques acinares y alrededor de los vasos sanguíneos. Esta fibrosis implica el establecimiento de nuevas barreras que impiden la difusión de metabolitos hacia los acinos, los cuales progresivamente se van compactando, disminuyendo de tamaño y generando la pérdida irreversible de funcionalidad de la glándula digestiva en las hembras Octopus mimus durante el ayuno fisiológico reproductivo. Estas alteraciones detectadas en Octopus mimus corresponden a una de las tantas modificaciones estructurales que se generan en los cefalópodos durante la senescencia posreproductiva.

Adicionalmente, las diferencias de los niveles de lípidos, carbohidratos y proteínas de la glándula digestiva, entre animales Octopus mimus en pre y posdesove, ponen en evidencia que este órgano es un buen indicador de la condición del animal y permite sustentar, en parte, la culminación del evento reproductivo. Para esto, la glándula digestiva invirtió el 91,6\% del total de las calorías que tenía acumuladas previas al desove; de las cuales el $57 \%$ fueron proporcionadas por los lípidos, el $32 \%$ por proteínas y el 11\% por glúcidos, contrastando con lo observado en el ayuno experimental prolongado en Sepia officinalis, en la que las proteínas realizaron el aporte energético mayoritario, seguido de lípidos y finalmente por los carbohidratos (Castro et al., 1992).

Junto con la glándula digestiva, el músculo también fue utilizado por Octopus mimus durante el ayuno reproductivo, produciéndose una merma de la masa la muscular coincidente con la observada en otros cefalópodos (ej. Illex illecebrosus), durante su permanencia en las zonas de desove (O'Dor \& Wells, 1987). La utilización del músculo, se debe al catabolismo de la musculatura durante el período previo al desove (O'Dor \& Wells, 1987) y al deterioro de la condición de la hembra al término del desove (Fields). Considerando los bajos niveles de lípidos presentes en la musculatura de Octopus mimus, al igual que los registrados en cefalópodos, las principales reservas de energía estarían almacenadas en las proteínas o en los carbohidratos del tejido muscular (Hochachka et al., 1975; O'Dor \& Weber, 1986). Consecuentemente, en el músculo de Octopus mimus, las proteínas fueron la fuente más importante de energía para sostener el evento reproductivo debido al catabolismo preferencial de las proteínas durante el ayuno, el cual fue detectado experimentalmente en Octopus vulgaris (Tait) y Sepia officinalis (Castro et al., 1992). En general se ha constatado que la mayoría de los cefalópodos, bajo condiciones deficientes de energía, utilizan las proteínas del manto como fuente de energía. Otras clases de animales como peces y 
mamíferos también utilizan diferentes grupos proteicos (enzimas, proteínas contráctiles y musculares) en diferentes rangos de magnitud durante los períodos de ayuno (Millward, 1970; Love, 1980).

Los glúcidos del músculo (29\%) de Octopus mimus, contribuyeron en gran parte al sostenimiento de la reproducción, contrastando con la poca importancia y bajo porcentaje $(0,56 \%)$ que tiene en Sepia officinalis (Storey \& Storey, 1983). Los lípidos de la musculatura de Octopus mimus fueron los de menor relevancia, coincidiendo con los bajos niveles de lípidos encontrados en la musculatura de otros octópodos (Suryanarayanan \& Alexander, 1971; Fujii, 1960). Durante el período posdesove, en Octopus mimus el contenido porcentual de las proteínas aumentó, aspecto que también ha sido mencionado en otros grupos de animales durante el ayuno: Balanus balanoides (Barnes et al., 1963); Artemia salina (Katavic et al., 1985); Brachionus plicatilis (Frolov \& Pankov, 1992). La reproducción y senescencia producen cambios en la apariencia de la musculatura del manto (Moltschaniwskyj, 1997), que evidencian las modificaciones en composición (O'Dor \& Wells, 1978; Pollero e Iribarne) y estructura (Moltschaniwskyj, 1995; Hatfield et al.) desarrolladas en este órgano, durante la producción de huevos. Sin embargo, existen algunas excepciones, en las especies semélparas Illex argentinus (Rodhouse \& Hatfield, 1992) y Loligo gahi (Guerra \& Castro, 1994). Durante la etapa posdesove, Octopus mimus no ingirió alimentos, promoviéndose la utilización de las miofibrillas como fuente energética. La merma de estos componentes citoplasmáticos produjo disminución de las dimensiones y volumen de las células musculares, que secundariamente inducen la fibrosis en el conectivo intercelular y en él de los septos musculares. Estas alteraciones son coincidentes con las observadas durante la senescencia posreproductiva en $O$. vulgaris (Tait). La alta fibrosis del tejido muscular de los brazos, al igual que el aumento de cenizas, asociados al posdesove de Octopus mimus corresponden a otro de los tantos procesos que se generan durante el envejecimiento posreproductivo de los cefalópodos. El incremento de las fibras colágenas, en los espacios extracelulares de todos los tejidos ha sido reconocido como el sitio primario de los cambios relacionados con la edad (Bailey \& Shimokomaki, 1971).

La maduración en hembras de $O$. mimus está asociada al crecimiento corporal, por lo que generalmente al término de la madurez sexual y previo al desove el cuerpo del animal y el ovario han alcanzando el mayor tamaño, pesando el ovario en promedio un $11 \%$ del peso corporal. El costo energético del crecimiento y desarrollo del ovario implicó almacenar en la gónada un total de $282,5 \mathrm{Kcal} / \mathrm{g}$, contenidas mayoritariamente en proteínas $(47,6 \%)$ y glúcidos $(45,1 \%)$ y en los escasos lípidos (4\%). Del total de esta energía aproximadamente el $90 \%$ quedó depositada en el vitelo de los huevos liberados por la hembras. Sin embargo, en huevos de otros cefalópodos se han detectado entre $14-19 \%$ de lípidos (Fujii; Bouchauad \& Galois, 1990), lo cual podría indicar variaciones de las rutas metabólicas entre embriones de diferentes especies.

La fecundidad de Octopus mimus está estimada entre 60.000 - 200.000 huevos (Warnke, 1999) y 50.000 400.000 (Castro et al., 2002). La fecundidad de Octopus mimus es similar a las especies que poseen larvas planctónicas [e.g. Octopus tetricus (Joll, 1983); Octopus cyanea (van Heukelem, 1983)]; superior a las que ponen huevos más grandes y del cual nacen crías bentónicas [e.g. Octopus bimaculoides, (Forsythe et al., 1983); Eledone moschata, (Boletzky, 1975)]; e inferior a las especies que no realizan cuidado parental de sus puestas y destinan más energía para producir una mayor cantidad de huevos, para asegurar el éxito reproductivo [e.g. Loligo opalescens (Hixon, 1983); Todarodes pacificus (Ikeda et al., 1993)].

La pérdida de la función reproductiva de Octopus mimus hembra, después de su única puesta de huevos, se debe a la carencia de células germinales parentales (ovogonias y ovocitos primordiales) en el ovario para promover un nuevo ciclo de formación de gametos. Adicionalmente, la actividad fagocítica de los macrófagos y la fibrosis del estroma gonadal contribuyen a la pérdida total del funcionamiento del ovario.

ZAMORA, C. M \& OLIVARES, P. A. Histological and biochemical variatios produced during the reproductive event of female Octopus mimus (Mollusca:Cephalopoda). Int. J. Morphol., 22(3):207-216, 2004.

SUMMARY: Octopus mimus has a semelparous modality of reproduction. Days before laying, females stop eating and their metabolism is sustained with energy stored in the body, dying after the paralarvae are born. Through histologic and biochemical study changes of the muscular tissue, digestive gland and ovary, associated to the only reproductive event of the female were verified. After spawning, the ovary does not has germinal cells that permit the development of a new reproductive cycle. The digestive gland and the muscle present atrophy of their cells, with a great increase of the connective tissue mainly of the collagen fibers. The proteins, glucids and lipids of the digestive gland and the muscle decrease in the period comprised between the laying and the eclosion of the eggs. The drastic biochemical alterations and the irreversible structural deterioration of the muscle and digestive gland reduce the life expectancy, in relationship to the degenerative changes that are developed in the female after the reproduction.

KEY WORDS: 1. Octopus mimus; 2. Reproduction; 3. Female; 4. Biochemistry; 5. Histology. 


\section{REFERENCIAS BIBLIOGRÁFICAS}

Bailey, A. J. \& Shimokomaki M. S. Age related changes in the reducible cross-links of collagen. FEBS Lett., 16:86-8, 1971.

Barnes, H.; Barnes M. \& Finlayson D.M. The seasonal changes in body weight, biochemical composition and oxygen uptake of two common boreo-artic cirripedes, Balanus balanoides and $B$. balanus. J. Mar. Biol. Ass. U.K., 43:185-211, 1963.

Bidder, A.M. The digestive mechanism of the European squids, Loligo vulgaris, Loligo forbesi, Alloteuthis media and Alloteuthis subulata. Q. J. Microsc. Sci., 91:1-43, 1950.

Bidder, A.M. Evidence for an absorptive function in the liver of Octopus vulgaris Lam. Pubbl. Stn. Zool. Napoli, 29:139-50, 1957.

Bidder, A.M. Feeding and digestion in Cephalopods. En: K.M. Wilbur and C.M. Yonge (eds.): Physiology of Mollusca. Academic press, New York, 1966. pp. 97-124.

Boletzky S.V. Le development D'eledone moschata (Mollusca, Cephalopoda) elevee au laboratoire. Bull. Soc. Zool. Fr. 100(3):361-7, 1975.

Boucad-Camou, E. \& Yim M. Fine structure and function of the digestive cells of Sepia officinalis (Mollusca: Cephalopoda). J. Zool., 193:89-105, 1980.

Boucad-Camou, E. \& Boucher-Rodoni R. Feeding and digestion in cephalopods. En: A.S.M. Saleuddin and K.M. Wilbur (eds.): The Mollusca, Vol. 5, part 2. Academic press, New York, 1983. pp. $149-87$.

Boucad-Camou, E.; Boucher-Rodoni R. \& Mangold K.. Digestive absorption in Octopus vulgaris (Cephalopoda: Octopoda). J. Zool., 179:261-71, 1976.

Bouchauad, O. \& Galois R.. Utilization of egg yolk lipids during the embryonic of Sepia officinalis in relation of temperature of the water. Comp. Biochem. Physiol., 97(3):611-5, 1990.

Boucher-Rodoni, R. \& Mangold K. Experimental study of digestion in Octopus vulgaris (Cephalopoda: Octopoda). J. Zool., 183:505$15,1977$.

Budelmann, B.; Schipp R. \&. Boletzky S.V. Microscopic Anatomy of Invertebrates. En: F.W. Harrison \& A.J. Kohn (eds.): Mollusca II. Vol. 6a, Wiley-Liss Inc., New York, 1997. pp 119 - 414.

Calow, P. The cost of reproduction. A physiological approach. Biol. Rev., 54:23-40, 1979.

Castro, B.G., Garrido J.L. \& Sotelo C.G.. Changes in composition of digestive gland and mantle muscle of the cuttlefish Sepia officinalis during starvation. Mar. Biol., 114:11-20, 1992.

Castro, H.; Olivares, A. \& Quintana, A. Descripción del desarrollo embrionario y paralarvas de Octopus mimus Gould 1852 (Mollusca: Cephalopoda) en cautiverio. Estud. Oceanol., 21:13-25, 2002.
Cortez, T.; Castro, B.G. \& Guerra, A. Reproduction and condition of female Octopus mimus (Mollusca: Cephalopoda). Mar. Biol., 123:505-10, 1995.

Cortez T. Growth of cultured Octopus mimus (Cephalopoda, Octopodidae). Fish. Res. 40(1):81-9. 1999.

Cuenot, L. Fonctions absorbante et excrétrice du foie des Céphalopodes. Arch. Zool. Exp. Gén. IVème Sér, 7: 218-45, 1907.

Fields, W. G. The structure, development food relations, reproductions and life stories of the squid Loligo opalescens Berry. Calif. Dep. Fish. Game. Fish. Bull., 131:1-108, 1965.

Forsythe J. W.; DeRusha, R.H. \& Hanlon, R.T. Notes on the laboratory culture of Octopus bimaculoides the California mudflat octopus. Am. Malacol. Bull., 2:92-3, 1983.

Frolov, A.V. \& Pankov S.L. The effect of starvation on the biochemical composition of the rotifer Brachionus plicatilis. J. Mar. Biol. Ass. U. K., 72: 343-56, 1992.

Fujii, T. Comparative biochemical studies on the egg yolk proteins of various animals species. Acta Embryol. Morph. Exp., 3:250-6, 1960.

Guerra, A. \& Castro, B.G. Reproductive somatic relationships in Loligo gahi (Cephalopoda: Loliginidae) from the Falkland island. Antartic Sci., 6:175-8, 1994.

Guerra, A. T. Cortez \& Rocha, F. Redescripción del pulpo de los Changos, Octopus mimus Gould, 1852, del litoral chileno - peruano (Mollusca, Cephalopoda: Octopodidae). Iberus, 17(2):3757, 1999.

Hatfield, E.; Rodhouse, P. G. \& Barber, D. L. Production of soma and gonad in maturing female Illex argentinus (Mollusca: Cephalopoda). J. Mar. Biol. Ass. U. K., 72:281-91, 1992.

Hixon, R. F. Loligo opalescens. En: P.R. Boyle (ed.): Cephalopod Life Cycles, Vol. 1. Academic press, London, 1983. pp. 95-114.

Hochachka, P.; Moon, T.W.; Mustafa, T. \& Storey, K.B. Metabolic sources of power for mantle muscle of a fast swimming squid. Comp. Biochem. Physiol., 52(B):151-8, 1975.

Ikeda, Y.; Sakurai Y. \& Shimazaki, K. Maturation process of Japanese common squid Todarodes pacificus in captivity. En: T. Okutani, R.K. O'Dor, \& T. Kuboreda (eds.): Recent advances in cephalopod fisheries biology. Tokai University, Tokyo, 1993. pp. 179-87.

Jackson, G. D. \& Mladenov, P.V. Terminal spawning in the deep-water squid Moroteuthis ingens (Cephalopoda: Onychoteuthidae). J. Zool., 234:189-201, 1994.

Joll, L.M. Octopus tetricus. En: P. R. Boyle (ed.): Cephalopod Life Cycles, Vol. 1. Academic Press, London, 1983. pp. 325-34. 
Katavic, I. ;Tudor, M.; Komljenovic, J. \& Ruzic, N. Changes in the biochemical composition of Artemia salina (L) in relation to different feedings condition. Acta Adriatica, 26(2):123-34, 1985.

Lillie, R. D. Histopatologic Staining Methods of the Armed Forces Institute of Pathology. McGraw-Hill Book Co. New York, $72 \mathrm{p}$. 1968.

López, M.; Leyton, C. \& Graf, M. Técnicas de histología y citología. $2^{\mathrm{a}}$ ed. Depto. de Biología Celular y Genética. Facultad de Medicina. Universidad de Chile, 242 p. 1982.

Love, R.M. The Chemical Biology of Fishes. Academic, New York, 1980. V. 2.

Mangold, K. M. \& Young R. E. The systematic value of the digestive organs. En: N. A. Voss, M. Vecchione, R. B. Toll, and M. J. Sweeney (eds.): Systematics and biogeography of cephalopods, Vol. 1, Smiths. Contr. Zool., 1998. 586(1):21-30.

Millward, D. J. Protein turnover in skeletal muscle II. The effect of starvation and protein free diet on the synthesis and catabolism of skeletal muscle proteins in comparison to liver. Clin. Sci., 39:591-603, 1970.

Moltschaniwskyj, N. A. Multiple spawning in the tropical squid Photololigo sp.: What is the cost in somatic growth?. Mar. Biol., 124:127-35, 1995.

Moltschaniwskyj, N.A. Changes in mantle muscle structure associated with growth and reproduction in the tropical squid Photololigo sp. (Cephalopoda: Loliginidae). J. Moll. Stud., 63:290-3, 1997.

Morales, E. Contribución al estudio de la morfología, estructura y anatomía microscópica de la región visceral de Pteroctopus tetracirrhus D. Ch. (Octopoda: Incirrata). Inv. Pesq., 37(2):355$518,1973$.

O'Dor, R. K. \& Weber D. M. The constraints on cephalopods: Why squid are not fish. Can. J. Zool., 64:1591-605, 1986.

O'Dor, R.K. \& Wells M.J.. Reproduction versus somatic growth: hormonal control in Octopus vulgaris. J. Exp. Biol., 77:529-40, 1978.

O'Dor, R.K. \& Wells M.J. Energy and nutrient flow. En: P.R. Boyle (ed.): Cephalopod Life Cycles, Academic press, London, 1987. pp. 109-33. V. 2.

O'Dor, R.K.; Mangold, K.; Boucher-Rodoni R.; Wells M. J. \& Wells J. Nutrient absorption, storage and remobilization in Octopus vulgaris. Mar. Behav. Physiol., 11:239-58, 1984.

Olivares, A.; M. Zamora, P.; Portilla \& O. Zúñiga. Estudio histológico de la ovogénesis y maduración ovárica en Octopus mimus (Cephalopoda: Octopodidae) de la II Región de Chile. Estud. Oceanol., 20:13-22, 2001.

Olivares, A., O. Zúñiga, G. Castro, C. Segura \& J. Sánchez. Bases biológicas para el manejo de Octopus mimus: Reproducción y crecimiento. Estud. Oceanol., 15:61-74, 1996.
Pollero, R.J. \& Iribarne, O. O. Biochemical changes during the reproductive cycle of the small Patagonian octopus, Octopus tehuelchus, D'Orb. Comp. Biochem. Physiol., 90(B):317-20, 1988.

Rodhouse, P.G. \& Hatfield. E. M. Production of soma and gonad in maturing male Illex argentinus (Mollusca: Cephalopoda). J. Mar. Biol. Ass. U.K., 72:293-300, 1992.

Sauer, W.H. \& M.R. Lipinski. Histological validation of morphological stages of sexual maturity in chokker squid Loligo vulgaris reynaudii D'Orb (Cephalopoda: Loliginidae). S. Afr. J. mar. Sci., 9:189-200, 1990.

Schmidt-Hebbel, H. Avances en Ciencia y Tecnología de los Alimentos. Alfabeta Impresores. Santiago de Chile, 1981.

Semmens, J.M. Structure and function of the cephalopod digestive gland and experimental study on Idiosepyus pygmaeus (Cephalopoda: Idiosepiidae). BSc. Hons Thesis, James Cook University of North Queensland, Australia, 1993.

Semmens, J.M.; Moltschaniwskyj, N. A. \& Alexander, C. G. Effect of feeding on the structure of the digestive gland of the tropical sepioid Idiosepius pygmaeus. J. Mar. Biol. Ass. U.K., 75:885-97, 1995.

Silby, R.M. \& Calow, P. Physiological Ecology of Animals. An evolutionary approach. Blackwell Scientific Publications, Oxford, 1986.

Storey, K.B. \& J.B. Storey. Carbohydrate metabolism in cephalopods molluscs. En: P.W. Hochachka (ed.): The Mollusca, Academic press, New York and London, 1983. V. 1. pp. 91-136.

Suryanarayanan, H. \& Alexander, K. M. Fuel reserves of molluscan muscle. Comp. Biochem. Physiol., 40(A):55-60, 1971.

Tait, R.W. Aspects physiologiques de la sénescence post reproductive chez Octopus vulgaris. Ph. D. Thése. L'Université Paris VI, 1986.

Tazi, M.; Catania, R. \& Boucad-Camou, E. Quantitative and morphometric study of boules in the digestive gland of Sepia officinalis. En: The Cuttlefish. 1st International Symposium on the cuttlefish Sepia, Caen, june 1989. France: Centre de Publications, University of Caen, 1991.

Van Heukelem W. F. Octopus cyanea. En: P.R. Boyle (ed): Cephalopod Life Cycles, Academic press, London, 1983. pp. 267-276. V. 1.

Warnke, K. Observations on the embryonic development of Octopus mimus (Mollusca: Cephalopoda) from Northern Chile. Veliger, 42(3):211-217, 1999.

Dirección para correspondencia:

Prof. Mauricio Zamora $C$.

Universidad de Antofagasta.

Facultad Recursos del Mar.

Departamento de Acuicultura.

Casilla 170.

Antofagasta - CHILE

E-Mail:m.zamora@vtr.net; aolivares@uantof.cl
Recibido : 08-06-2004

Aceptado: 19-07-2004 